ARTIGO ORIGINAL

\title{
O IMPACTO NEGATIVO DOS TRANSTORNOS DO USO E ABUSO DO ÁLCOOL NA CONVIVÊNCIA FAMILIAR
}

\author{
THE NEGATIVE IMPACT OF THE DISTURB OF THE USE AND ABUSE OF THE ALCOHOL IN THE FAMILY \\ COEXISTENCE
}

\section{EL IMPACTO NEGATIVO DEL TRASTORNE DEL USO Y ABUSO DEL ALCOHOL EN LA CONVIVENCIA FAMILIAR}

\section{Francisco Arnoldo Nunes de Miranda ${ }^{1}$, Clélia Albino Simpson ${ }^{2}$, Dulcian Medeiros de Azevedo ${ }^{3}$, Shirley da Silva Costa ${ }^{4}$}

RESUMO: O uso e abuso do álcool progride de forma lenta e insidiosa evoluindo para cronificação acarretando imensuráveis problemas no processo saúde-doença do indivíduo e da família em todo o mundo. O presente estudo analisou o impacto negativo na convivência familiar relacionado aos transtornos do uso e abuso do álcool. Trata-se de uma pesquisa de campo com abordagem qualitativa centrada nos desabafos de familiares proferidos espontaneamente no ato da admissão de um serviço de urgência psiquiátrica na região metropolitana do Natal/RN. O instrumento técnico-metodológico da coleta de dados foi a escuta ativa-pesquisa. A partir dos modelos explicativos os desabafos foram agrupados, predominando o moral associado ao ético-legal. Os achados revelam que o modelo explicativo moral do uso e abuso de álcool é mais bem explicado pelos familiares, embora o sentido moralizante também seja captado nas falas que ilustram os demais modelos. Verificamos uma dificuldade em aceitar a condição de doente, mesmo que o alívio das tensões decorrentes do cuidar do alcoolista seja o hospital. Muitas são as propostas explicativas e terapêuticas para a problemática, todavia não podemos perder de vista a necessidade de promover ações educativas permanentes que garantam aos portadores e familiares uma maior compreensão dos problemas vivenciados e uma melhor adequação dos anos vividos ajustados a capacidade perdida em virtude de todas as alterações ocorridas no decurso do uso e abuso do álcool em seu processo saúde-doença.

PALAVRAS-CHAVE: Alcoolismo; Família; Enfermagem.

ABSTRACT: The use and abuse of the alcohol progress in a slow and insidious way developing for chronic disease carting immeasurable problems in the individual's process health-disease and of the family all over the world. The present research study analyzed the negative impact in the family coexistence related to the upset of the use and alcohol abuse. It is treated of a field research with qualitative approach centered in the relatives' relieves uttered spontaneously in the act of the admission of a service of psychiatric urgency in the metropolitan area of Natal City/RN. The technician-methodological instrument of the data collection was based on the active listening research. Starting from the explanatory models where the relieves were contained, prevailing the morals associated to the ethical-legal. The discoveries reveal that the model explanatory morals of the use and abuse of alcohol is better explained by the relatives, although the moralize sense is also captured in the speeches that illustrate the other models. We verified one it refuses in accepting the patient condition, even if the relief of the current tensions of taking care of the alcoholic is the hospital. Many are the explanatory and therapeutic proposals for the problem, though we cannot lose of view the need to promote permanent educational actions that guarantee to the bearers and family a larger understanding of the lived problems and a better adaptation of the years lived adjusted the lost capacity by virtue of all the alterations happened in the continuation of the use and abuse of the alcohol in your process health-disease.

KEY WORDS: Alcoholism; Family; Nursing.

RESUMEN: El progreso del uso y abuso del alcohol de una manera lenta e insidiosa que desarrolla para enfermedad crónica que carretea los problemas inmensurables en la salud-enfermedad del proceso del individuo y de la familia por el mundo. El estudio de la investigación presente analizó el impacto negativo en la coexistencia familiar relacionada al disgustado del uso y abuso del alcohol. Se trata de una investigación del campo con acercamiento cualitativo centrado en los parientes releva proferido espontáneamente en el acto de la admisión de un servicio de urgencia psiquiátrica en el área metropolitana de Natal/RN. El instrumento técnicometodológico de la colección de los datos era establecido en la investigación de escucha activa. Empezando de los modelos explicativos dónde el releva se contuvo, mientras prevaleciendo las morales asociadas al ético-legal. Los descubrimientos

\footnotetext{
1 Prof. Dr. do Departamento de Enfermagem, Universidade Federal do Rio Grande do Norte - UFRN. E-mail: farnoldo@ibest.com.br Base de Pesquisa - Enfermagem Clínica BCD-108-01. Capim Macio - Natal/RN.

2 Profa ${ }^{2} r^{a}$ do Departamento de Enfermagem, Universidade Federal do Rio Grande do Norte - UFRN. Natal/RN E-mail: cleliasimpson@pop.com.br

Enfermeiro. Bolsista CAPES. Mestrando do Programa de PósGraduação em Enfermagem - DENF/CCS./UFRN. Natal/RN Email: dulcianenf@hotmail.com

4 Monitora do Projeto de Ensino: Viva a Vida sem Muros do Hospital-Dia Dr. Elger Nunes - DENF/CCS/UFRN. Natal/RN. Email: shirlinha enf@yahoo.com.br
} 
revelan que las morales explicativas ejemplares del uso y abuso de alcohol son explicadas bien por los parientes, aunque el moralice el sentido también se captura en los discursos que ilustran a los otros modelos. Nosotros verificamos uno que se niega a aceptando la condición paciente, aun cuando el alivio de las tensiones actuales de cuidar del alcohólico es el hospital. Muchos son las propuestas explicativas y terapéuticas para el problema, aunque nosotros no podemos perder de vista que la necesidad de

\section{INTRODUÇÃO}

O Brasil através da III Conferência Nacional de Saúde Mental, além de reafirmar a saúde como direito do cidadão e dever do Estado propõe a necessidade de garantir, nas três esferas de governo, que as políticas de saúde mental sigam os princípios do Sistema Único de Saúde (SUS) com atenção integral, acesso universal e gratuito, equidade, participação e controle social em respeito às diretrizes da Reforma Psiquiátrica [Lei 10.216, de 16/04/2001] e das Leis Federal e Estaduais e da construção da rede de atenção integral em saúde mental (BRASIL, 2002).

A legislação brasileira garante aos portadores de transtornos mentais a acessibilidade, direitos e cidadania a partir do fornecimento de maior número de informações sobre seu adoecimento e atendimento nos serviços de saúde, de qualquer natureza, a pessoa e seus familiares ou responsáveis cujos direitos são formalmente informados. Ao atendê-los garante 0 melhor tratamento do sistema de saúde, consentâneo às suas necessidades por meio de intervenções com humanidade e respeito cujo interesse exclusivo é o de beneficiar sua saúde, visando alcançar sua recuperação pela inserção na família, no trabalho e na comunidade.

Diariamente, como profissionais enfermeiros(as), constatamos que o processo de trabalho nos serviços de saúde mental e psiquiátrica, adota modelos de intervenção baseados, além do modelo biomédico, outros modelos substitutivos e complementares, como também aqueles outros intuitivamente decorrente da experiência individual na área e, ainda na concepção sistematizada da assistência. Dessa forma, não encerra uma mera questão funcional e operacional, no seu fazer mais tradicional, mas adotam modelos híbridos cujas intervenções apontam para o aspecto humano centrado na pessoa e nas relações psicossociais, revelando assim, uma preocupação e uma tendência para além dos sintomas psicopatológicos manifestos.

Freqüentemente os serviços de urgência e emergência psiquiátrica atendem casos de alcoolismo, que é uma das grandes dependências da humanidade, pois sabemos que em todos os povos independentes da etnia, religião, gênero, condição promover acciones educativas permanentes que garantizan a los portadores y familia una comprensión más grande de los problemas vividos y una adaptación buena de los años vivida ajustado la capacidad perdida en virtud de todas las alteraciones pasó en la continuación del uso y abuso del alcohol en su salud-enfermedad del proceso.

PALABRAS-CLAVE: Alcoholismo; Familia; Enfermería.

social o consumo de substâncias alcoólicas é um hábito ou um estilo presente na convivência humana em diferentes momentos do seu acontecer. Este comportamento é carregado de forte simbolismo cultural por estar circunscrito aos rituais religiosos, comemorações e confraternizações em geral

O uso e abuso do álcool progridem de forma lenta e insidiosa evoluindo para cronificação acarretando imensuráveis problemas no processo saúde-doença do indivíduo, da família e da sociedade. Nesta perspectiva, entendemos que os efeitos psicológicos, sociais, culturais, jurídicos, políticos e econômicos da dependência do uso e abuso do álcool acarretam prejuízos incalculáveis com redução das condições e qualidade de vida constituindo num ônus direto para o próprio usuário, bem como seus familiares, além das incapacidades biopsicossociais que se instalam no transcurso do uso e abuso gerando, indiretamente oportunidades perdidas no manejo do processo produtivo, social, afetivo e familiar, para simplificar a complexidade do problema, sem, contudo, esquecermos do aspecto de criminalidade que, alguns casos encerram

Observamos na admissão, freqüentemente, nos casos de uso e abuso de álcool a forte carga emocional e psico-afetiva que o ato em si encerra, gerando uma arena de conflitos permeadas por insultos, choros, desabafos e atitudes coercitivas e, olhares fuzilantes e repressores, além dos rompantes de heteroagressividade verbal e física que se inicia no domicílio ou na via pública até a formalização da admissão e início do tratamento. Dessa forma, o ato admissional destes casos torna-se um objeto de efeitos defensivos e ansiogênicos para todos os envolvidos, pois apesar da formação e atuação na área cada caso é um caso, com toda a sua potencialidade e vulnerabilidade cujo fato por si encerra.

O profissional de saúde, especialmente o enfermeiro, daí nossa inferência, se vê na confluência de um cuidar marcado pela polarização. De um lado, o posicionamento do alcoolista ao recusar o tratamento num hospital considerado como de "tratamento para loucos", embora reconheça, mesmo que minimamente que seu estado requer um tratamento. Este muito mais pelo próprio processo de desgaste bio-psicossocial e financeiro é marcado por forte relação de agressão-frustação, além da 
atribuição da culpa à família ou a membros distintos e ou a transferência de sua condição a outrem, quer pessoal, quer profissional e, ainda uma conjunção explicativa híbrida para sua farmacodependência. Do outro, a posicionamento da família, também não menos ansiogênica e defensiva, na busca do apoio e da solução para as dificuldades decorrentes deste processo. Freqüentemente, a família faz-se representar por um membro familiar que assume esta condição de cuidador e, assim defende os interesses da família, embora carregue nas suas manifestações discursivas o peso e o ônus suportivo da situação traduzidos em desabafos.

Curiosamente, passamos a olhar este aspecto da negociação negada entre familiar e alcoolista no ato da admissão, que se caracteriza como uma manifestação discursiva e cotidiana através da escuta-ativa. Entendida como um processo centrado na relação humana entre o terapêuta e a pessoa que requer ajuda com formação de vínculo e da confiança, proporcionando um espaço de reflexão conjunta sobre valores, atitudes e condutas manifestas com a finalidade de dar um sentido de orientação e/ou reordenação dos conteúdos psíquicos, criando oportunidades discursivas e operacionais de acordo com a capacidade da pessoa. Dessa forma, oportunizar o compartilhamento das dúvidas, sentimentos, conhecimentos, dentres outras demandas.

Assim, frequentemente nos perguntávamos: o que o familiar diz sobre ele, sobre si e quais os fragmentos indicativos da convivência familiar? Qual a importância da apreensão desses conteúdos verbais para melhorar o processo admissional, minimizando os desgastes emocionais e psicoafetivos como um componente terapêutico? Como auxiliar os familiares e obter a co-participação para juntos melhorar a adesão do alcoolista ao tratamento, compreendendo seu processo de adoecimento e da convivência familiar, reduzindo o déficit de inadequação no manejo da problemática e ampliando as possibilidades de uma melhor convivência a partir de esclarecimentos sobre o uso e abuso de álcool, recaída e seus mecanismo intrínsecos e extrínsecos circunscritos? Todos estes questionamentos se constituíram em um campo de interesse dos autores, embora neste estudo abordamos apenas um recorte destes.

Frente aos desafios dos familiares que dizem o que pensam e sentem e a ousadia dos autores, de antemão traçamos como objetivo analisar os desabafos de familiares no ato da internação de algum dos seus membros com história de uso e abuso do álcool, através da escuta-ativa.

Entendemos que o desabafo reflete o impacto negativo e a condição suportiva da convivência familiar, sem contudo menosprezar os laços de consangüinidade, parentalidade e de amizades, tampouco sentimentos positivos na convivência familiar quando não relacionados aos transtornos do uso e abuso do álcool, embora, ambos estejam conformados independente do grau, duração e intensidade. Portanto, não constitui objeto deste artigo, pois a preocupação dos autores remete a esfera do cuidar no contexto dos serviços de saúde mental e psiquiátricos como uma estratégia e um campo alternativo da atuação do profissional enfermeiro.

\section{Compreendendo o alcoolismo e sua interface com o Modelo Explicativo Assistencial de Saúde Mental}

No Brasil, do ponto de vista epidemiológico, um levantamento domiciliar sobre uso de drogas psicotrópicas realizado pelo Centro Brasileiro de Informações sobre Drogas Psicotrópicas (CEBRID) do Departamento de Psicobiologia da Universidade Federal de São Paulo, em 107 cidades com população acima de 200 mil habitantes com pessoas de 12 a 65 anos, 68,7\% faz uso do álcool (GALDURÓZ et al 2005). Estima-se que a dependência de álcool no país seja de $11,2 \%$, o que representa cerca de 5.283 .000 pessoas (VAISMAM, 1998).

O álcool se constitui na segunda causa mais freqüente de internações psiquiátricas e representa a causa de $32 \%$ dos leitos ocupados em hospitais gerais. O alcoolismo é o quinto responsável por consultas ambulatoriais (VAISMAM, 1998).

Para KAPLAN \& SADOCK (1995) o conhecimento da história natural da adicção favorece a possibilidade de entender melhor os transtornos mentais e como se diferenciam, em muitos aspectos das enfermidades físicas. Assim, as condições de consumo de uma substância psicoativa, configuramse, tanto como um problema de saúde mental, como de saúde pública e os efeitos nocivos do consumo são complexos e se descrevem como um continuum que varia com a intensidade (freqüência de uso e quantidade consumida) e a duração do consumo.

No mundo ocidental, é fato que cerca de 90\%da população adulta consome algum tipo de bebida alcoólica. Também é fato que, entre estes $10 \%$ irá apresentar um uso nocivo de álcool e outros $10 \%$ se tornará dependente, o que vale dizer que, em cada pessoas que consomem álcool, um terá um agravo de saúde por ingerir bebida alcoólica. Os estudos etiológicos tentam discriminar o que este bebedor tem de diferente dos demais, pois enquanto aqueles têm apenas prazer com o consumo de bebidas alcoólicas, as quais, inclusive, podem thes prover certo efeito protetor de inúmeras afecções clínicas, este se torna, com o tempo, portador de uma das enfermidades mais desgastantes do ponto de vista da saúde, tanto sua quanto de sua família (RAMOS \& WOITOWITZ, 2004).

PILON \& LUIS (2004) constataram que há uma produção significativa de experiências com a prática da enfermagem na assistência, pesquisa e ensino relacionado ao alcoolismo, o que tem gerado 
alguns modelos de intervenção para a abordagem desse grupo. Estes modelos retratam formas de entendimento das dimensões do problema do consumo de álcool e drogas, onde cada enfoque se concentra exclusivamente em um subconjunto ou aspecto dos fenômenos gerais.

As experiências revisadas pelas autoras apontam para modelos explicativos no cuidado a pessoa com problemas relacionados ao uso do álcool, originando formas de tratamentos para o caso, tais como o modelo ético-legal, o moral, o médico ou da doença, o psicológico ou psicossocial e, o sociológico ou sociocultural. Na perspectiva dessas autoras, existe entre os profissionais de enfermagem, em geral, grande necessidade de aquisição de conhecimentos teóricos que propiciem a revisão dos modelos ou protocolos informais que embasam a prática nessa área (PILON \& LUIS, 2004).

O modelo ético legal para PILON \& LUIS (2004, p.677), está relacionado:

"aos profissionais de direito e segurança social. Segundo as proposições teóricas desse enfoque, as causas estão nas atitudes antisociais e/ou imorais de certos grupos de transgressores. Nesse modelo, considera-se o problema como basicamente qualquer ato de transgressão que requer interferência baseada em sua sanção legal; não há aprofundamento da análise da dependência da substância e dos processos que a determinam. As drogas e seu consumo são importantes e requerem a atenção na medida em que se apresentam como causadores de danos graves aos indivíduos e à sociedade. A intervenção preventiva se apoia em medidas de caráter positivo e punitivo, operando por meios dos sistemas legislativo, judicial e policial".

No modelo moral de acordo com PILON \&

LUIS (2004, p.678) os indivíduos são:

"considerados responsáveis tanto pelo início e o desenvolvimento do problema, quanto pelas soluções e acredita-se que necessitam apenas de motivação apropriada. A principal limitação do modelo moral é que as pessoas são levadas a sentir-se culpadas pelo desenvolvimento do problema e a pensar que, de alguma forma, Ihes faltam força de vontade ou "fibra moral", por não conseguirem alterar com sucesso seu comportamento".

O modelo médico ou de doença segundo

PILON \& LUIS (2004, p.678):

"baseia-se na suposição de que a dependência de substâncias psicoativas seja entidade nosológica distinta e de caráter progressivo, com origens ou manifestações físicas e necessita de tratamento médico. Diversas entidades têm se empenhado em que seja utilizado o termo "dependência em detrimento de outros com maior conotação moral" (vício) e que esse problema seja visto como um conjunto de sintomas clínicos. O conceito do alcoolismo como doença foi proposto inicialmente por Jellinek, em 1960. Nesse modelo, o comportamento do uso da substância é visto como progressivo, incurável e a causa da doença está relacionada aos fatores genéticos, biológicos, estruturais de natureza química, tal como tem mostrado alguns estudos".

Esse modelo também implica em aceitar que o uso da substância exerce papel de doença e o indivíduo espera ser tratado como doente. $\mathrm{O}$ enfoque do tratamento implica na recuperação do uso, abuso e/ou dependência da substância, sendo a abstinência total, o objetivo a ser alcançado. Como exemplo, dentro desse enfoque estão os grupos de auto-ajuda (AA -Alcoólicos Anônimos). A intervenção preventiva, nesse modelo, centra-se no valor que as pessoas dão à saúde e fundamenta a educação no conhecimento da ação e prejuízos de determinadas drogas sobre o organismo, bem como as modificações que provocam sobre o comportamento e atitudes das pessoas. Nesse modelo o indivíduo conscientizado pela educação recebida evita o uso abusivo" (PILON \& LUIS, 2004, p.678).

O modelo psicológico ou psicossocial, revisado por PILON \& LUIS (2004, p.678) remete a idéia do aprendizado social.

"Dessa forma, propõe que o comportamento social é aprendido através da observação e imitação. Isto é, mostra que o exemplo dos pais é um importante fator no padrão inicial do consumo de substâncias, especialmente naquelas pessoas com habilidades sociais precárias. O uso do álcool é socialmente adquirido, os padrões de comportamento aprendidos são mantidos por fatores cognitivos, pela influência de modelos, expectativas e indicadores, e pela interação do comportamento com reforços do meio, incluindo também os fatores genéticos. $O$ ambiente familiar é visto como parte importante na determinação do consumo do álcool e sugere que o alcoolismo está consistentemente associado com negligência, distanciamento emocional, rejeição dos pais e tensão familiar. A atribuição de características específicas de personalidade, no caso do uso de substâncias, estaria associada a muitos fatores, dentre eles a falta de maturidade, conflitos intrapessoais e interpessoais, baixa auto-estima, ou ter como base "problemas psiquiátricos como depressão ou transtorno de ansiedade, dentre outros".

O modelo sociológico ou sociocultural identificados por PILON \& LUIS (2004:679) concebe a problemática das drogas como:

"resultado de um número de forças sociais. A sua explicação a respeito do uso de substâncias enfatiza a função do meio cultural com suas crenças, valores e atitudes que 
conduzem a comunidade ou seus grupos específicos no caminho da abstenção ou do uso de drogas. É um modelo ambientalista, que destaca a importância do ambiente na conduta do indivíduo; na interação de elementos sociológicos (do grupo ou subcultura à qual ele pertence) e culturais (costumes e tradições). Para esse modelo, atitudes culturais com relação ao uso de droga psicoativa podem exercer função importante na determinação do comportamento individual. $\mathrm{Em}$ algumas culturas, a abstinência pode ser regra e em outras o uso pode ser parte de um ritual religioso e cerimonial ou aceito como droga social ou recreacional".

Ainda no contexto desse modelo, os fatores sociológicos tais como o desemprego, a privação social, e outros, podem ter efeitos importantes sobre o início e o uso continuado da substância pelo indivíduo. Também o sexo, idade, religião, etnia, condições socioeconômicas e ambiente familiar influenciam diretamente na opção individual de usar ou não a substância. A ação preventiva proposta por esse modelo tem como objetivo fundamental a mudança nas condições sociais dirigidas a grupos marginalizados, visando a melhora da qualidade de vida e sua integração na comunidade (PILON \& LUIS, 2004).

Concordamos com COIMBRA et al (2005, p.103) que uma assistência de enfermagem deva atender "a demanda do indivíduo e de sua família" e que "requer um aprendizado que ultrapasse os conceitos teóricos da reforma psiquiátrica". Assim, exige habilidades e competências adquiridas no manejo diário e experiencial, assim como no aprender a aprender com os múltiplos saberes que advém da prática da enfermagem na busca da inclusão social e na implementação das ações para um cuidar adequado as constantes modificações desse agir terapêutico.

\section{O CAMINHO METODOLÓGICO}

Ao optarmos por um aspecto da comunicação verbal que diz respeito aos conteúdos manifestos captados através dos desabafos dos familiares no ato da admissão do familiar com transtornos comportamentais decorrentes do alcoolismo, circunscrevemos o estudo no âmbito da pesquisa qualitativa.

$$
\text { Segundo MINAYO (1993, p.10): }
$$

"as metodologias de pesquisa são capazes de incorporar a questão do significado e da intencionalidade como inerentes aos atos, às relações e às estruturas sociais, sendo estas últimas tomadas tanto no seu advento quanto a sua transformação, como construções humanas significativas".

Para POLIT \& HUNGLER (1995, p.270): "a pesquisa qualitativa costuma ser descrita como holística (preocupada com os indivíduos e seu ambiente, em todas as suas complexidades) e naturalista (sem qualquer limitação ou controle impostos ao pesquisador".

Destarte, trata-se de uma pesquisa de campo com enfoque em desabafos/relatos de familiares (esposas, mães, filhas, cunhada e pai) proferidos espontaneamente no ato da admissão de um serviço público de urgência psiquiátrica do Município do Natal/RN integrante do Sistema Único de Saúde, no período de maio a junho de 2005 , onde a maioria dos autores exerce atividades profissionais na assistência de enfermagem em regime de plantão, e os demais no ensino, extensão e monitoria por ser campo das práticas curriculares do Curso de Graduação da UFRN. O instrumento técnico-metodológico da coleta de dados foi a escuta ativa-pesquisa.

Segundo TAKEUTI (2002) a escuta ativapesquisa como metodologia privilegia a espontaneidade dos relatos, pois utiliza de uma abordagem não-diretiva, em busca de uma aproximação do cotidiano das famílias em relação à problemática do alcoolismo. Entendemos que, se de um lado 0 método flexibiliza 0 argumento metodológico, portanto mais objetivo, do outro a explicação descritiva do objeto de investigação revela a subjetividade dos sujeitos. Em ambos casos, o rigor e a validade, a fidedignidade e a validade devem ser perseguidas para dar a sustentação dos achados.

Ao diferenciar a abordagem psicoterapêutica da intenção de pesquisa TAKEUTI (2002) diz que a escuta terapêutica trata de elucidar os processos psíquicos e de identificar os mecanismos de defesa presentes na produção do sintoma do paciente [ou do sujeito em questão numa pesquisa], portanto, focaliza a problemática do sujeito. A escuta na esfera da pesquisa, está centrada nas dimensões que ultrapassam o sujeito em si, articulando as dimensões sociais na compreensão de problemas singulares (individuais ou grupais) imbricados no objeto de investigação.

A compreensão do cotidiano situa o pesquisador, objeto-sujeito da ação, como produtor de sentidos sobre o contexto, redimensionando-o, tanto pelas verossimilhanças, quanto pelos estranhamentos derivados das relações estabelecidas entre ele e o objeto da apreensão. Nesse sentido, concordamos com RICHARDSON \& PERES (1999) quando chama-nos a atenção para o aspecto multifacetado da observação uma vez que ela apresenta várias nuances em face de sua flexibilidade que diz respeito ao objetivo que delimita o objeto a partir da decisão pela forma de observação, o preparo do seu desenvolvimento, o desempenho de seu emprego propriamente dito e o seu registro. Acrescentaríamos ainda a análise e a interpretação.

A partir deste posicionamento metodológico, optamos pelo critério da não intencionalidade, assim 
como alguns protocolos sobre a observação em modelos mais tradicionais na pesquisa. Captar através da escuta de pesquisa as falas dos familiares sobre a pessoa com transtornos relacionados ao álcool, precisamente os desabafos, requer o exercício da sensibilidade. Dessa forma, priorizamos o momento da admissão no serviço em estudo que exigiu autores uma atenção redobrada, mesmo que, na maioria das vezes este ato é acompanhado com certo alvoroço gerando um clima de tensão entre os familiares e carregado de intenso desabafo ou impropérios.

Sabedores deste ruído procuramos filtrar o momento no conjunto da fraseologia aquele que mais expressava o impacto negativo na convivência familiar. Estar atento, aos procedimentos de rotina de um serviço de urgência psiquiátrica, agir terapeuticamente e, ainda captar o que era dito pelos familiares requereu de todos um repensar de sua prática, no que diz respeito à escuta-ativa como forma de apreensão da realidade. Imediatamente, aos encaminhamentos do caso registrávamos os desabafos seguidos da identificação do paciente/usuário e familiar para posterior apresentação ao mesmo.

A coleta ocorreu em jornadas de trabalho distintas de acordo com o regime de trabalho dos autores. Assim, na relação presencial exigiu uma atenção acurada sobre o que diziam os familiares a respeito da pessoa em atendimento de urgência psiquiátrica além das manifestações psicopatológicas relatadas.

Não consideramos importantes os prováveis critérios da Classificação dos Transtornos Mentais e do Comportamento (CID-10) da Organização Mundial de Saúde (1993) sobre o uso e abuso do álcool para os casos atendidos naquele serviço de urgência psiquiátrica. Intencionalmente, priorizamos a cena da admissão e seu contorno afetivo, emocional e psicossocial manifesto pelos familiares.

O critério de inclusão não fez distinção entre gênero, cor, raça e condição sócio-econômica uma vez que os sujeitos configuravam a demanda espontânea atendida, com prevalência do gênero feminino na busca do atendimento, e do masculino com problemas relacionados ao alcoolismo. Vale ressaltar que não desconsideramos a importância e a relevância destes indicadores sócioantropométricos, porém não foram definidos para este estudo embora estivessem disponíveis no prontuário.

O estudo seguiu os parâmetros da resolução 196/96 do Conselho Nacional de Saúde, a qual direciona os princípios éticos de pesquisas realizadas com seres humanos, embora o ato da coleta em si não se caracteriza uma abordagem direta aos familiares, pelos instrumentos mais tradicionais, o ato de fala aprendido exigiu uma atenção e um refinamento para captar através da escuta-ativa as dificuldades e rupturas da convivência familiar. Nesse sentido consideramos uma possibilidade de técnica encoberta para apreender os desabafos dos familiares assegurando o sigilo e a confidencialidade das palavras ou frases proferidas sobre seus familiares. Assim garantimos os preceitos bioéticos autonomia, não-maleficência, beneficência e justiça.

Todos os familiares participantes do estudo, tão logo após o ato admissional foram esclarecidos sobre o objetivo da pesquisa com apresentação dos registros de falas coletados e transcritos pelos autores que, depois de lidos cuidadosamente, assinaram o Termo de Consentimento Livre e Esclarecido sem nenhum conflito de interesses. Nessa oportunidade, coletamos dados gerais do familiar. A pesquisa aprovada pela Direção Geral do Serviço de Saúde Mental tido como local de pesquisa, também auferiu o direito de sua citação na divulgação dos resultados.

Levamos em consideração alguns dos aspectos éticos fundamentais nas questões familiares. Segundo NELSON \& NELSON (1995) os membros da família são vinculados uns aos outros e que a necessidade de intimidade produz responsabilidade, e assim, fazer com que uma pessoa exista produz responsabilidades, portanto, as famílias são histórias em andamento, pois nas famílias os motivos contam muito.

O material coletado foi submetido a leitura flutuante na busca e apreensão das unidades de fala que se enquadravam nos modelos explicativos sobre o alcoolismo segundo PILON \& LUIS (2004) definidos na revisão da literatura para analisar os desabafos dos familiares, entendidos e considerados como manifestações discursivas dos mesmos sobre o alcoolista no momento da internação.

\section{OS DESABAFOS COMO RESULTADOS DISCUSSÃO DA CONVIVÊNCIA FAMILIAR}

Os desabafos dos treze familiares participantes do estudo foram codificados de acordo com o manuseio do material coletado cuja identificação foi feita com a letra $D$, seguida de numeral ordinal seqüencial na medida em que foram apreendidos, observado e discutidos a partir do Quadro Sinóptico 1. Também, sob o ponto de vista do familiar e da enfermagem.

Os sujeitos participantes são, majoritariamente, do gênero feminino, excetuando-se um pai. Destes, cinco eram esposas, duas companheiras com relação estável e filhos, cuja prole variou de um a três filhos, incluindo uma adoção, duas mães, duas irmãs e uma cunhada por ser auxiliar de serviços gerais. Esta composição heterogênea, a grosso modo, reflete uma tradição do cuidar familiar relegando a mulher a responsabilidade de cuidar do membro familiar alcoolista.

Ressaltamos, com base no Quadro Sinóptico 1, que uma dada fala catalogada numa das opções do modelo explicativo, também pode ser inscrita num outro, uma vez que na prática tais posicionamentos 
MIRANDA, F. A. N.; SIMPSON, C. A.; AZEVEDO, D. M.; COSTA, S. S. o impacto negativo dos transtornos do uso e abuso do álcool na convivência familiar. Revista Eletrônica de Enfermagem, v. $08, \quad n . \quad 02, \quad$ p. $222 \quad-\quad 232, \quad 2006 . \quad$ Disponível em http://www.fen.ufg.br/revista/revista8_2/v8n2a07.htm

estão impregnados de valores éticos, morais, tabu, preconceito, estigma e discriminação. Mediante leitura flutuante

seguimos 0 critério da intencionalidade.

Quadro Sinóptico n. 1. Unidades de falas identificadas com os Modelos Explicativos para uso do álcool e drogas. Serviço Público de Urgência Psiquiátrica, Natal-RN. Maio/Junho 2005.

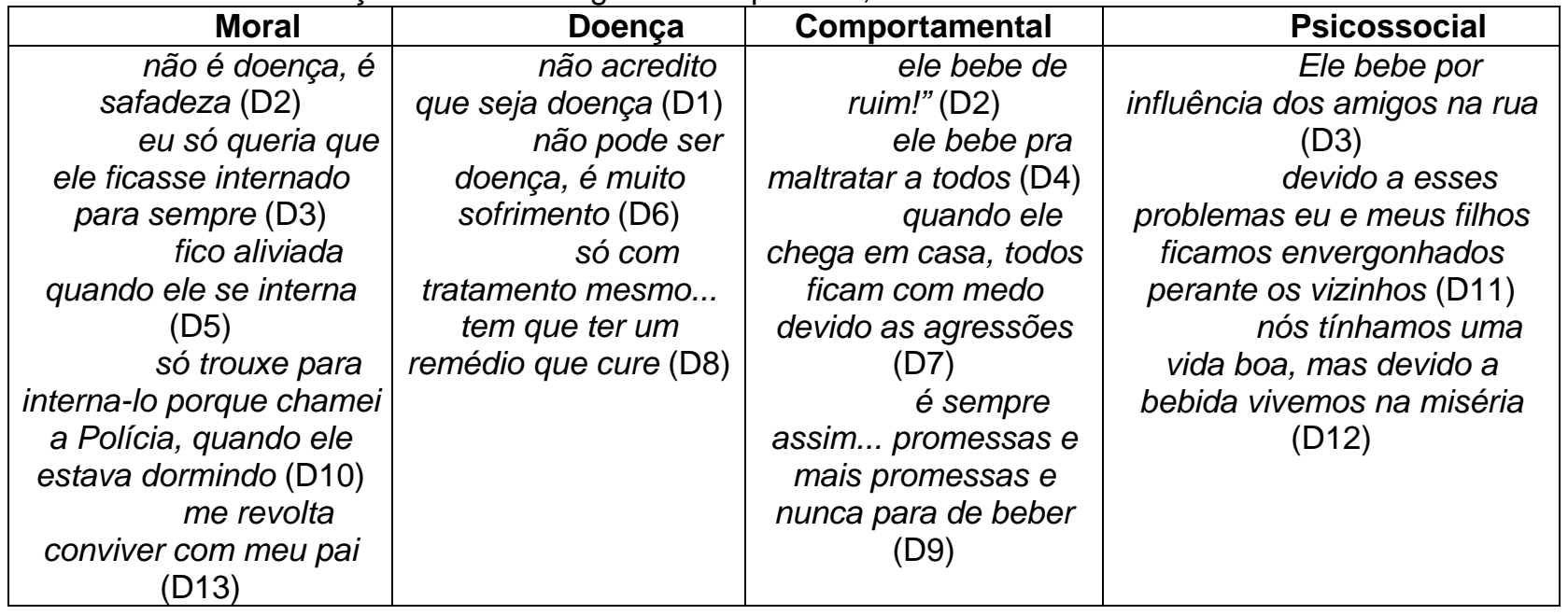

Os achados revelaram que o modelo explicativo moral do uso e abuso de álcool é mais bem explicado pelos familiares, embora o sentido moralizante também seja captado nas falas que ilustram os demais modelos. Verificamos uma recusa em aceitar a condição de doente, mesmo que o alívio das tensões decorrentes do cuidar do alcoolista seja o hospital, um local reconhecido socialmente como um lugar de cura, por ser medicalizado. Se de um lado, o aspecto moral requer um sentido punitivo, por outro justifica o desgaste da família com o problema, seja pela precarização das condições de vida, seja pela ruptura das relações afetivas, parentalidade e social. Assim, o comportamento agressivo do familiar é decorrente ou influenciado por outras pessoas, também julgados moralmente por ser responsável de todo o infortúnio familiar, e daqueles outros familiares que não Ihes pertence e que, na mesma condição sofre as auguras desse acontecer humano.

Concordamos com COIMBRA et al (2005a, p.100) que a família no contexto da contemporaneidade sofre o impacto da pósmodernidade (cultural), do neoliberalismo (político) e da globalização (econômico), também "sofreu transformações marcadas pela pluralidade e diversidade com relação aos padrões até então vigentes, em geral, solidamente, de ordem sentimental moralizada".

$\mathrm{Em}$ todos os desabafos observamos a concepção ético-legal por estar associado à dificuldade no manejo e na convivência com o alcoolista, assim como a agressividade como provável desfecho das dificuldades da convivência familiar.

Alguns poucos familiares chegaram ao serviço de forma mais contida, sem falar nada, embora aparentasse profundo sentimento de tristeza, desalento, vergonha e medo em sua expressão facial.
Esses mantiveram-se com postura de alheiamento com o desenrolar da situação, atendo-se aos procedimentos corriqueiros de admissão. Esse movimento nos sugeria um comportamento meio amorfo, como se estivesse se desbotando juntamente com a situação/problema. Esse fato também nos chamou a atenção, porém por não se tratar do foco de nosso estudo, sugere uma averiguação sistematizada a posteriori.

Os resultados da pesquisa também são comentados sob dois pontos de vista: o da família e da enfermagem. Dessa forma, entendemos que a busca de novas tecnologias frente a Lei $n^{\circ} 10.216$ de 04 de junho de 2001, especificadamente no que refere o Art. $2^{\circ}$ e seu parágrafo único e incisos, se constitui como um mecanismo de consolidação da reforma psiquiátrica e da melhoria da convivência familiar e adesão da mesma nos recursos psicoterapêuticos e dos processos de trabalho do profissional enfermeiro nos seriços de urgência e emergência psiquiátrica..

\section{Do ponto de vista dos cuidados da Família}

Reconhecemos que as interações do profissional enfermeiro com um indivíduo são também interações indiretas com a família dele, porque a família é segundo SMELTZER \& BARE (2001) um sistema dinâmico porque a incapacidade de um membro afeta os membros da convivência familiar. Apenas com a incorporação desta no processo de reabilitação, pode o sistema familiar adaptar-se à mudança em um de seus membros.

Da mesma forma que para Hirdes apud COIMBRA et al (2005) ao creditar a família como protagonista do processo de tratamento psiquiátrico, ou seja, como co-participante e não como um sistema desequilibrado cujo membro alcoolista reflete o adoecimento da mesma no seu funcionamento social, 
valoriza a capacidade da família como um sistema capaz de efetivamente resolver situações/problemas, intervir nas crises e promover a recuperação do seu membro com problemas de uso e abuso do álcool.

Entendemos que dessa parceria assimétrica entre serviços de saúde, usuários e familiares e equipe multiprofissional, não somente são redefinidos os papéis destes atores, mas, principalmente aqueles que sempre foram e serão assumidos pela família, independentes da tão proclamada co-participação, pois independentemente de redefinição conceitual ela sempre esteve participante do tratamento do portador de transtorno mental em geral, especialmente nas situações de uso e abuso do álcool, por ser ela a primeira a ser afetada na sua dinâmica funcional e organizacional. Este fato, por si mesmo, requer da família reajustes para manter-se adequada e ajustada aos desequilíbrios decorrentes desse processo. Também, por sofrer estigma e discriminação através de estereótipos, como por exemplo, a responsabilidade da família pela doença do paciente esteve presente nas formas adotadas de tratamento psiquiátrico, seja o hospitalocêntrico, seja o modelo substitutivo, com maior ou menor aproximação e distanciamento com a questão, pois estando sob a responsabilidade, freqüentemente de um único cuidador familiar, os demais membros também sofre em graus variados de aproximação e distanciamento o impacto negativo desse acontecimento.

Da experiência e convivência com os comportamentos manifestos pelo uso abusivo do álcool a família proporciona e aprende a dar cuidado contínuo necessário. Ademais é essencial a compreensão de família como a mais constante unidade de saúde para seus membros no que diz respeito ao seu funcionamento e aos fatores que influenciam as experiências de mesma, seja na saúde, seja na doença.

O funcionamento familiar segundo ANGELO \& BOUSSO (2001) focaliza as necessidades de seus membros as quais devem ser atendidas. Estas são pautadas em conhecimento e familiaridade com rotinas de cuidado, além da capacidade para detectar sinais de doença com base em evidências muitas vezes despercebidas aos outros. Devido às suas características próprias de proximidade e convivência, a família tem melhores condições para acompanhar os processos de saúde e de doença de seus membros.

Prosseguindo, as autoras afirmam que todas as famílias são portadoras da cultura da sociedade em que vivem e da qual se identificam refletindo nos estilos de vida, valores, ideais, crenças e práticas as quais estão impregnadas em suas definições e transmitidas de geração para geração, afetando o comportamento e, conseqüentemente, o estado de saúde da família. Dessa forma, as estratégias que a família utiliza para lidar com as demandas influenciam a sua saúde e funcionamento. O enfrentamento pode ser definido como respostas positivas de natureza afetiva, cognitiva e comportamental que a família utiliza para resolver ou reduzir o estresse produzido por um evento ou problema (ANGELO \& BOUSSO, 2001).

\section{Do ponto de vista dos cuidados de Enfermagem}

$\mathrm{Na}$ esfera do exercício profissional da enfermagem, entendemos que apesar da crença de que todo o comportamento tem uma finalidade e visa satisfazer uma carência ou comunicar uma mensagem, combinada com um sentimento de curiosidade pelo significado do comportamento do cliente por parte do profissional enfermeiro, este aspecto aparentemente trivial por ser cotidiano constitui a base do princípio de que a mesma explora o comportamento do paciente em busca de respostas terapêuticas capazes de atender a necessidade a partir da mensagem que está sendo comunicada.

Nesse sentido, pelo diagnóstico é possível identificar através das manifestações comportamentais os padrões para dar respostas imediatas aos problemas identificados. Este atendimento reducionista por si mesmo não dá conta da complexidade, da polifonia e da ambigüidade que a situação/problema decorrente dos transtornos relacionados ao álcool encerra. O manejo e o funcionamento inadequado do usuário na família tende a ser reaplicado e redimensionado proporcionalmente nos cenários dos serviços de saúde, característica esta levada em conta na agenda terapêutica para o alcoolista e, particularmente, para a família. Esta, ao compreender este manejo inadequado pode efetivamente cooperar no processo de reabilitação psicossocial do seu membro familiar. O grau de dificuldade que esta questão encerra, vai depender da disposição da família e do alcoolista em resolver este problema, carregado de intensa descarga emocional e afetiva numa situação de projeção de expectativas e anseios, seguidos da relação agressão-frustração. Romper estes padrões adctivos e estereotipados requer ainda suportes sociais mais compreensivos e tolerantes para a questão, além dos cuidados e suportes emanados dos serviços de saúde mental e psiquiátrico.

Podemos inferir que para o conjunto de falas apresentadas (Quadro Sinóptico n.1), respeitada a singularidade de cada pessoa com transtornos decorrentes do uso excessivo do álcool, identificado na fala do familiar em situação de desabafo, mas ousando ampliar para o caráter da generalização, concordamos com TAYLOR (1992) que um bom indício é adotar estratégias que sejam capazes de reafirmar a auto-estima do indivíduo. Portanto, esse deve se constituir no objetivo central de todo o atendimento de enfermagem para a pessoa e para a família. Lidar com situações limítrofes, como observamos em nossa prática hospitalar nas situações limítrofes, requer de cada profissional enfermeiro uma avaliação das potencialidades e vulnerabilidades decorrentes de sua prática, um 
contínuo senso investigativo que ao gerar conhecimento das informações verbais ou contextuais, além das formas de silêncio ou ocultamento da problemática, gera saberes e práticas mais adaptadas e, portanto, mais humanizadas no atendimento ao alcoolista e família.

Dessa forma, inferimos que nos casos observados o alcoolista e/ou o dependente de substâncias psicoativas sob a ótica da avaliação de enfermagem, geralmente, revelam retardo ou hiperatividade psicomotora, alteração ou déficit de funcionamento social e familiar, desleixo com vestuário, aparência e hábitos higiênicos mal conservados, padrões de sono e despertar alterados, alteração das funções psíquicas com comprometimento dos estados mentais, prejuízo nos processos interpessoais, sexualidade altera, atenção fraca ou hiperalerta, comprometimento no padrão alimentar, potencial de violência auto e heterodirigida, impotência e desesperança, dentre outras incapacidades perdidas, além das oportunidades.

Portanto, a avaliação de enfermagem segundo TAYLOR (1992), deve em linhas gerais contemplar os padrões de atividade da vida diária, os processos de conhecimento, ecológico, emocionais, interpessoais, de percepção, fisiológicos e de validação que foram identificados anteriormente como sinais e sintomas do alcoolista no parágrafo anterior.

Salientamos que os modelos existem para explicar e descrever as evidências e os padrões comuns que, também, dão pistas para o planejamento dos cuidados de enfermagem na área da dependência química que no campo da operacionalização, essa prática, muitas vezes, tem emergido de forma alternada e direcionada para cada caso sem a devida compreensão dos modelos que se interfaceam. Por isso mesmo, sem simplificar a problemática, nem sempre tem atendido as especificidades dos usuários de substâncias psicoativas e seus familiares.

$\mathrm{Na}$ perspectiva da família, concordamos com SCATENA (2000) quando afirma que a família, direta ou indiretamente, afeta e é afetada por todas as intervenções da Enfermagem Psiquiátrica e que o processo de reabilitação envolve o indivíduo, família, comunidade e profissionais.

$\mathrm{Na}$ perspectiva da atenção básica, corroboramos com COIMBRA et al(2005) ao afirmarem que existe a necessidade de oferecer uma atenção mais abrangente como forma de pensar, fazer saúde e trabalhar a saúde mental na comunidade na Estratégia Saúde da Família. Nesse sentido, a estratégia não significa apenas o atendimento de programas pré-estabelecidos (hipertensão, diabetes, pré-natal, dentre outros), mas um atendimento universal, abrangente e integral para a comunidade, visando a realidade social e suas necessidades de saúde dentro da família.

Concluímos que os princípios básicos para a assistência aos usuários de álcool e outras drogas, não se diferenciam das demais áreas da enfermagem, todavia, requer a necessidade de promover a aliança terapêutica através de um ambiente acolhedor, relação empática (fundamental para a motivação) guiada pelo relacionamento interpessoal. Dessa forma, segundo PILON \& LUIZ (2004) garantem uma assistência integral e contínua, consolidando a competência coletiva do trabalho da equipe através do estabelecimento de boa comunicação para o trabalho cooperativo.

\section{CONSIDERAÇÕES FINAIS}

Ao nos apropriarmos dos quatro modelos explicativos para entender os desabafos dos familiares, observamos que para estes sujeitos, o modelo ético-legal aparece interfaceado com o modelo moral. Dessa forma, os estados psicoafetivos dos familiares, pressupomos que por ser utilizado no manejo do tratamento do álcool as falas dos familiares, expressam fragmentos desses modos de intervenção até mesmo pela influência da conivência com o linguajar utilizado nos serviços de saúde e da própria mídia.

Assim, a experiência profissional na definição e opção por estes modelos, também refletem o modo como a família se aproxima da problemática, talvez sem nenhuma ou pouca clareza dos aspectos conceituais e metodológicos deste ou daquele agir terapêutico, mas que detém um conhecimento e uma sensibilidade para procurar formas de superação do problema familiar.

Se de um lado, observamos os juízos de valores expressos na admissão, por outro, entendemos como um sentido de que cuidar de familiar alcoolista gera penosidade. Esta, como um serviço domiciiliar, pouco valorizado, repetitivo, cansativo e que causa sofrimento pessoal e familiar na medida em que sucedem as recaídas gerando expectativas situadas na dimensão do desacreditável/desacreditado pois o manejo e a eficácia psicoterapêutica vão de encontro aos interesses do cuidador, ou seja, curar ou reduzir consideravelmente os efeitos indesejáveis no núcleo familiar do alcoolismo. Por penosidade, também entendemos como um sentido manifesto que produz dor, sofrimento, desânimo, pena incômodo e sensação de impotência. Destarte, a obrigação e ou a imposição para cuidar de familiares com transtornos do álcool, pode ter sido uma escolha não negociada e até negada, cuja única opção acarreta um continnun onerável e imensurável em suas vidas exigindo formas de silenciamento e/ou exaltação da singular e real situação familiar. Nesse sentido, especialmente no momento da admissão, é carregado de muita tensão e de desgaste físico e emocional os aspectos da afetividade são redimensionados para os sentimentos negativos desse ônus sócio-familiar.

Do outro, tornou-se claro para nós a singularidade do ato de admitir chamando-nos a 
atenção para a vulnerabilidade e a potencialidade como um caminho para amenizar essa situação de penosidade das partes envolvidas, incluída as do profissional enfermeiro.

Ao atendermos essas pessoas não tínhamos muita clareza de como trabalhar com essas falas, mas o perceber este movimento como um aspecto trivial do atendimento, despertou em nós autores a curiosidade para entender um pouco melhor este desabafo nestas circunstâncias.

O que significava e o que estava significando o modo de justificar sua presença ao lado de alguém com problemas com o alcoolismo? $\mathrm{O}$ que nos diz isso tudo como enfermeiros? Será uma fresta que dá acesso a uma complexa rede explicativa da convivência familiar afetada pelo uso e abuso do álcool familiar? Ou seria uma confissão de que não tenho nada a ver? "Se tenho não é minha culpa, apenas por falta de opção carrego este fardo". Ainda, não encontramos todas respostas, mas certamente por esta fresta penderemos a ver o que é possível captar e estabelecer uma relação de ajuda mediante a escuta-ativa.

Nesta perspectiva, a ampliação do compromisso da enfermagem no atendimento desses casos requer uma forma particularizada de compreender a situação/problema para além da dramaticidade da cena, a qual deve ser atendida com respeito, dignidade e cuidados adequados, mas como um alargamento dos limites do campo de atuação de um fazer humanizado da enfermagem nos serviços psiquiáricos.

Ao adotar o agir centrado na dimensão desse encontro humano, além dos aspectos bio-psico-social do atendimento emergencial, o profissional enfermeiro pode identificar pontos de estrangulamento da convivência familiar, que são indicadores desse comportamento manifesto através de ações educativas em saúde e da visita domiciliária. Portanto, na medida em que este portavoz familiar, entendido como aquele que se responsabiliza pela busca dos serviços de emergência psiquiátrica, também exige um atendimento compreensivo para o seu desabafo com respeito, dignidade através de uma acolhida humanizada, pois sua fala dá dicas de que necessita de socorro para dar conta das fragilidades e rupturas do vínculo familiar.

Consideramos relevante que a educação em saúde seja um compromisso social do enfermeiro que se insere como fundamental no campo da enfermagem psiquiátrica para assegurar não só o atendimento do cliente, mas de sua família, sobre os problemas relacionados ao uso crônico do álcool. Assim, como é imprescindível a orientação do paciente sobre o seu problema valorizando a família como parte integrante desta estratégia com a garantia de acesso à informação e aos meios de tratamento disponíveis na comunidade, incluindo um tratamento mais intensivo, se necessário, além das redes sociais de apoio.

Em qualquer circunstância do uso e abuso do álcool é essencial trabalhar com a família, além do próprio paciente os conceitos de síndrome de dependência, abstinência alcoólica, co-morbidade, desintoxicação e a auto-estima, assim como a prevenção da recaída e a reintegração social.

O agir terapêutico centrado na transformação da informação em conhecimento tanto para o alcoolista, como para a família propicia uma açãoreflexiva que, no mínimo, tem como objetivo desenvolver, neste sistema familiar, suportes psicossociais para dar resolutividade à situação/problema que por sua vez, redefinirá os velhos e os novos papéis assumidos ou não pelos membros que constituem o núcleo familiar afetado minimizando o ônus oculto que o problema encerra.

Muitos são os desafios, assim como muitas são as propostas terapêuticas para o uso e abuso de álcool. Todavia não podemos perder de vista a necessidade de promover ações educativas em saúde na perspectiva da integralidade das ações e do resgate da visita domiciliaria como um fazer sistemático que garanta aos portadores de transtornos relacionados ao álcool e familiares uma melhoria dos anos vividos ajustados a capacidade perdida em virtude de todas as alterações ocorridas no decurso do uso e abuso do álcool.

\section{REFERÊNCIAS BIBLIOGRÁFICAS}

ANGELO, M.; BOUSSO, R.S. Fundamentos da assistência à família em saúde. In.: BRASIL. Ministério da Saúde. Secretaria de Assistência à Saúde. Manual de Enfermagem: temas de caráter introdutório. Brasília, 2001.

BRASIL. Presidência da República. Casa Civil. Subchefia para Assuntos Jurídicos. Lei $n^{\circ} 10.216$, de 6 de abril de 2001. Dispõe sobre a proteção e os direitos das pessoas portadoras de transtornos mentais e redireciona o modelo assistencial em saúde mental. Brasília, 2001. Disponível: http://www.planalto.gov.br/ccivil 03/Leis/LEIS 2001/L 10216.htm [Acesso em 18 mai. 2006].

BRASIL. Sistema Único de Saúde. Conselho Nacional de Saúde. Comissão Organizadora da III CNSM. Relatório Final da III Conferência Nacional de Saúde Mental. Brasília, 2002.

COIMBRA, V.C.C. et al. A atenção em saúde mental na estratégia saúde da família. Revista Eletrônica de Enfermagem [on line], Goiânia, 2005. Disponível em: http://www.fen.ufg.br/revista/revista7 1/revisao 03.ht m [Acesso em 17 mai. 2005].

COIMBRA, V.C.C. et al. Reabilitação psicossocial e família: considerações sobre a reestruturação da assistência psiquiátrica no Brasil. Revista Eletrônica de Enfermagem [on line], Goiânia, 2005a. Disponível em: 
http://www.fen.ufg.br/revista/revista7 1/revisao 01.ht $\underline{m}$ [Acesso em 18 mai. 2005].

GALDURÓZ, J.C.F. et al. Uso de drogas psicotrópicas no Brasil: pesquisa domiciliar envolvendo as 107 maiores cidades do país - 2001. Rev. Latino-am Enfermagem, Ribeirão Preto, v.13. n. esp., p.888-895, 2005.

KAPLAN, H.I., SADOCK, B.J. Medicina psiquiátrica de emergência. Porto Alegre: Artes Médicas, 1995.

MINAYO, M. C. S. O desafio do conhecimento:

pesquisa qualitativa em saúde. São Paulo: Hucitec-

Abrasco, 1993.

NELSON H.L.; NELSON, J.L. The patient in the family: an ethics of Medicine and families. New York: Routledge, 1995:74.

PILON, S.C.; LUIS, M.A.V. Modelos explicativos para o uso de álcool e drogas para a enfermagem. Rev Latino-am Enfermagem, Ribeirão Preto, v.12, n.4. p.676-682, 2004.

POLIT, D. F.; HUNGLER, P. B. Fundamentos de Pesquisa em Enfermagem. 3. ed. Porto Alegre: Artes Médicas, 1995.

RAMOS, S.P.; WOITOWITZ, A.B. Da cervejinha com os amigos à dependência de álcool: uma síntese do que sabemos sobre esse percurso. Rev Bras Psiquiatria, São Paulo, v.26, supl. I, p.18-22, 2004.

RICHARDSON, R.J.; PERES, J.A.S. Pesquisa social: métodos e técnicas. São Paulo: Atlas, 1999.

SCATENA. M.C.M. Saindo do hospital psiquiátrico: análise da reinserção dos pacientes nos lares abrigado. [Livre-Docência] Ribeirão Preto: Universidade de São Paulo. Escola de Enfermagem de Ribeirão Preto, 2000.

SMELTZER, S.C.; BARE, B.G. Brunner/Suddart Tratado de enfermagem médico-cirúrgica. Rio de Janeiro, Guanabra-Koogan, 2001.

TAKEUTI, N. No outro lado do espelho: a fratura social e as pulsões juvenis. Rio de Janeiro: RelumeDumará, 2002.

TAYLOR, C.M. Fundamentos de enfermagem psiquiátrica de Mereness. Porto Alegre: Artes Médicas, 1992.

VAISMAM M. Alcoolismo com problema de saúde no trabalho: avaliação de um programa para tratamento para funcionários de uma universidade. Rio de Janeiro: UFRJ, 1998. 